\title{
Disaster Risk Assessment in Educational Hospitals of Qazvin Based on WHO Pattern in 2015
}

\author{
Saeed Asefzadeh ${ }^{1}$, Ali Safari Varyani², Soheyla Gholami ${ }^{3}$
}

${ }^{1}$ Ph.D. of Health Care Management, Professor, Social Determinants of Health Research Center, Qazvin University of Medical Sciences, Qazvin, Iran

${ }^{2}$ Ph.D. Of Occupational Health Engineering, Associate Professor, Department Of Occupational Health Engineering, Faculty Of Health, Qazvin University Of Medical Sciences, Qazvin, Iran

${ }^{3}$ M.Sc. Student of Health Care Management, Social Determinants of Health Research Center, Qazvin University of Medical Sciences, Qazvin, Iran

\section{Type of article: Original}

\begin{abstract}
Introduction: In addition to damaging communities and infrastructures, unexpected disasters affect service provider centers as well. Structural, non-structural, and functional components of hospitals could be affected when hazards or disasters occur, and they may be unable to admit casualties, have their own personnel and patients killed or injured, have their property destroyed. In such as case, they would increase the burden of death resulting from the disaster. Therefore, in this study, hospital safety was reviewed in two hospitals in Qazvin in 2015.

Methods: This cross-sectional descriptive study was conducted on two of the Rajaee and Velayat Hospitals in Qazvin. The tools used to assess for the hospitals' risk of experiencing a disaster were observation, interviews, and a checklist of hospital disaster risk assessment provided by the World Health Organization (WHO), including 5 sections and 145 indices for the safety assessment of hospitals. To determine the general weight, three main parts of the questionnaire, i.e., functional safety, non-structural safety, and structural safety, were given weights of $0.2,0.3$, and 0.5 , respectively, according to the original version of the indices. Each index was scored as 0,1 , and 2 based on the low, medium, and high scores. The safety scores that were obtained were categorized in three groups, i.e., low safety $(\leq 34 \%)$, medium safety $(34-66 \%)$, and high safety $(>66 \%)$. The data were analyzed using Excel 2007 software.

Results: Functional, structural, and non-structural safety scores were evaluated as $60.20 \%$ (medium safety), $67.61 \%$ (high safety), and $76.16 \%$ (high safety), respectively. General preparedness of the hospitals we studied were $71.90 \%$, a high safety level. This high preparedness was related to the indices of availability of medicines, equipment, water supply, and other resources required in emergency conditions (85\%), and the lowest preparedness was related to contingency plans of medical operations $(19 \%)$.

Conclusion: The preparedness of the two hospitals in the study was evaluated as being high. Considering the history of disasters in this Province, it would be effective to retrofit hospitals and compile written plans for administrative measures at the time of disasters. These measures must be consistent, and there should be safe installation of risky office and medical equipment.
\end{abstract}

Keywords: disasters, risk assessment, hospital, Qazvin

\section{Introduction}

In the last decade, incidents of unexpected disasters have increased around the world in such a way that the rate of mortality has been about 106,000 people per year (1). Relatively all nations are exposed to various unexpected disasters, including hurricanes, floods, earthquakes, fires, drought, terrorist attacks, volcanic eruptions, chemical accidents, and disease. Natural disasters can start quickly or slowly and can have serious adverse impacts on health

\section{Corresponding author:}

Soheyla Gholami, Social Determinants of Health Research Center, Qazvin University of Medical Sciences, Qazvin, Iran. Tel: +98.9108383690, Email: sohailagolami@yahoo.com

Received: October 08, 2015, Accepted: November 24, 2015, Published: January 2016

iThenticate screening: November 24, 2015, English editing: December 30, 2015, Quality control: January 05, 2016 (C) 2015 The Authors. This is an open access article under the terms of the Creative Commons Attribution-NonCommercialNoDerivs License, which permits use and distribution in any medium, provided the original work is properly cited, the use is non-commercial and no modifications or adaptations are made. 
and social levels as well as economic consequences (2). After India, Bangladesh, and China, Iran stands fourth in terms of unexpected natural disasters (3) in such a way that of 40 natural disasters reported around the world, 31 cases have occurred in Iran, and they are likely to occur again in the future (4). Since most natural disasters cannot be prevented, WHO considers it vital to increase the preparedness of the healthcare system, especially hospitals, so that appropriate services can be provided for casualties (5). Hospitals and service providers should keep work continuously and do whatever they can to assist injured people when disasters happen. Therefore, having a solid and resistant structure could help hospitals in these disasters $(6,7)$. In some instances, hospitals are directly affected by the disasters, and they can incur structural, non-structural, and equipment damages, injuries to medical staff and other personnel, and even organizational and managerial issues. In such conditions, they would not be capable of providing services to the casualties of the disaster (8). In 2005, 168 countries constructed hospitals according to Hyogo framework resistant to disasters with flexibility and strengthened the functional capacity against disasters (9). According to WHO's estimates, about 18,000 medical centers and hospitals are exposed to losses and damages of disasters in the Pan American Health Organization (PAHO) region. The Bam earthquake in Iran (2003), tsunami (2004), and flood (2007) in Indonesia devastated and destroyed many hospitals and healthcare centers. In the Bam earthquake, $100 \%$ of the facilities were demolished; the tsunami destroyed $61 \%$ of healthcare structures in Indonesia, and three hospitals and 20 healthcare centers in Maldives, 92 healthcare facilities, including 35 hospitals and 40 service providers in Sri Lanka, along with 40 service providers in Indonesia were damaged by the flood (10). When disasters and accidents happen, work conditions in hospitals change completely. Therefore, hospitals could have the best performance when disasters occur it they are prepared to cope with disasters (11) and have the best performance by correct assessment of possible disasters. This assessment could be conducted in structural, nonstructural, and functional domains. The structural elements are those parts of a building that support it (such as pillars, ceilings, walls, and floors) and resist gravity, earthquakes, hurricanes, and other imposed forces that account for $15 \%$ of hospital building costs. Non-structural elements consist of facilities, equipment, and architectural factors of hospitals that account for $85 \%$ of construction costs $(12,13)$.

The functional dimension consists of managerial aspects and having a plan to stand against disasters $(14,15)$. In a study conducted by Mirzaei et al. investigating the preparedness of Ilam's hospitals, they stated that hospital safety is medium during disasters in the functional, structural, and non-structural domains (16). Qazvin is a seismic zone in Iran, and disasters, including earthquakes, floods, drought, frostbite, icy roads, landslides, and extensive vehicle accidents are very likely there. Because of being close to Alborz industrial city, there is the possibility of fires and explosions. There is a history of earthquakes that measured 7.2 on the Richter scale in 1962 in Buin Zahra, a 6.5 earthquake in Avajin in 2002, and 5.0 earthquakes in 2005 in Alamut, creating the most significant disasters in this Province, with significant loss of life and damage to property (17). Thus, it seemed to be necessary to conduct a study in the hospitals in this Province. The aim of this study was disaster risk assessment in two general hospitals with the highest admission rates in Qazvin Province. Rajaee Hospital was selected since it is trauma center in the region, and Velayat Hospital was selected because it consists of specialty and subspecialty clinics that have made it a medical center with a high admission rate.

\section{Material and Methods}

This cross-sectional study was a practical research project that was conducted in Velayat and Rajaee Hospitals related to the Qazvin University of Medical Sciences in 2015. The tools used in this study of the disaster risk assessment in hospitals were observations, interviews, and hospital disaster risk assessment checklist of WHO, which was localized by Ardalan et al. (18). This form consists of five sections and 145 indices of hospitals' disaster risk assessments with subtitles of general information about the hospital, recognizing risks, functional, nonstructural, and structural safety assessment. To determine the general weight, three major parts of the questionnaire, including functional, non-structural, and structural safety, were considered as $0.2,0.3$, and 0.5 , respectively, in accordance with the original version of the index, and each index was given scores of 0,1 , or 2 according to whether the scores received were low, medium, or high. Considering the obtained safety score, it was categorized into low ( $\leqslant 34 \%$ ), medium (34-66\%), and high ( $>66 \%)$ safety groups according to WHO's indices (19). The data were analyzed using Excel 2007.

\section{Results}

Table 1 shows the preparedness of hospitals in the study in coping with disasters. The overall means of functional, structural, and non-structural safety were assessed as $60.20 \%$ (medium safety), $67.61 \%$ (high safety), and 76.16\% (high safety), respectively, in the two hospitals. The overall preparedness of the hospitals in the study was $71.90 \%$, which was high with regard to divisions of level of safety and amount of safety in these two hospitals. Functional 
safety of the two hospitals was assessed in five domains, and the results are shown in Table 2. The highest preparedness of $90 \%$ was related to availability of medicines, equipment, and required resources in emergency conditions in Velayat Hospital, and the lowest preparedness of $6.25 \%$ was related to the index of contingency plans for medical treatment in Rajaee Hospital. Non-structural safety of two hospitals was assessed in nine domains, and the results are presented in Table 2. The highest preparedness of $100 \%$ was related to the index of the water supply system in Velayat Hospital and the lowest preparedness of $42.85 \%$ was related to heating, ventilation, and airconditioning (HVAC) systems in critical areas of Rajaee Hospital. Structural safety of two hospitals was assessed in two domains, and the results are provided in Table 2. The highest preparedness of $100 \%$ was related to previous events affecting safety of Velayat Hospital, and the lowest preparedness of $60 \%$ was related to the structural safety system and type of materials used in construction in Rajaee Hospital.

Table 1. The percentage of General preparedness of the hospitals that were studied

\begin{tabular}{|l|l|l|l|}
\hline Safety component & Velayat Hospital & Rajaee Hospital & Mean \\
\hline Functional capacity & 65.70 & 54.71 & 60.20 \\
\hline Non-structural & 72.48 & 62.75 & 67.61 \\
\hline Structural & 95 & 63.33 & 76.16 \\
\hline Total Safety (Given Weight) & 82.38 & 61.43 & 71.90 \\
\hline
\end{tabular}

Table 2. The percentage of Preparedness of the hospitals in coping with disasters

\begin{tabular}{|c|c|c|c|c|}
\hline $\begin{array}{l}\text { Safety } \\
\text { component }\end{array}$ & Safety element & $\begin{array}{l}\text { Velayat } \\
\text { Hospital }\end{array}$ & $\begin{array}{l}\text { Rajaee } \\
\text { Hospital }\end{array}$ & Mean \\
\hline \multirow[t]{5}{*}{$\begin{array}{l}\text { Functional } \\
\text { capacity }\end{array}$} & $\begin{array}{l}\text { Organization of Hospital Disaster Committee and } \\
\text { Emergency Operations Center }\end{array}$ & 70.83 & 66.66 & 68.74 \\
\hline & Operational plan for internal or external disasters & 73.91 & 45.65 & 59.78 \\
\hline & Contingency plans for medical treatment in disasters & 31.25 & 6.25 & 18.75 \\
\hline & $\begin{array}{l}\text { Plans for the operation, preventive maintenance, and } \\
\text { restoration of critical services }\end{array}$ & 62.5 & 75 & 68.75 \\
\hline & $\begin{array}{l}\text { Availability of medicines, supplies, instruments, and } \\
\text { other equipment for use in emergency }\end{array}$ & 90 & 80 & 85 \\
\hline \multirow{9}{*}{$\begin{array}{l}\text { Non- } \\
\text { structural }\end{array}$} & Electrical system & 81.25 & 43.75 & 62.5 \\
\hline & Telecommunications system & 92.85 & 42.85 & 67.85 \\
\hline & Water supply & 100 & 70 & 85 \\
\hline & Fuel storage & 87.5 & 50 & 68.75 \\
\hline & Medical gases & 57.14 & 78.57 & 67.85 \\
\hline & $\begin{array}{l}\text { Heating, ventilation, and air-conditioning (HVAC) } \\
\text { systems in critical areas }\end{array}$ & 85.71 & 42.85 & 64.28 \\
\hline & $\begin{array}{l}\text { Office and storeroom furnishings and equipment (fixed } \\
\text { and movable) including computers, printers, and other } \\
\text { equipment }\end{array}$ & 50 & 50 & 50 \\
\hline & $\begin{array}{l}\text { Medical and laboratory equipment and supplies used for } \\
\text { diagnosis and treatment }\end{array}$ & 55.55 & 95 & 75.27 \\
\hline & Architectural elements & 88.88 & 69.44 & 79.16 \\
\hline \multirow[t]{2}{*}{ Structural } & Previous events affecting the safety of hospital buildings & 100 & 66.66 & 83.33 \\
\hline & $\begin{array}{l}\text { Safety of structural systems and materials used in } \\
\text { building }\end{array}$ & 90 & 60 & 75 \\
\hline $\begin{array}{l}\text { Total Safety } \\
\text { (Free Weight) }\end{array}$ & & 77.72 & 58.91 & 68.31 \\
\hline
\end{tabular}

\section{Discussion}

The findings of this study showed that the overall mean of safety in the two hospitals in the study was $71.90 \%$, which was assessed as high according to WHO standards (19). In a study by Glif et al. in a rural hospital in the United States, preparedness of these hospitals was assessed as $0.78 \%(20)$, which was in agreement with the results of our study. Sabzghabaie et al. assessed a preparedness of $49.44 \%$ against disasters for Shahid Beheshti Hospital 
(21), which did not agree with the results of our study. In the study conducted by Zhong et al. on 41 hospitals in China, the preparedness of hospitals in the study was $81 \%$ (22), which was close to our results. In addition, in a study conducted on 45 hospitals in the Caribbean, only $2 \%$ of hospitals were of relatively good safety, $80 \%$ of medium safety, and $18 \%$ of low safety, which were different from the results of our study (23). The difference between the general preparedness of hospitals in terms of separate domains would be related to several factors, including differences in the research environment, the method used to collect data, oral interviews, written questionnaire or observation, when the data were collected, the training and expertise of the people who collected the data, the type of checklists used, and relatively long-period studies. In this study, the preparedness of the hospitals we studied was $60.20 \%$ in domain functional safety, which was assessed to be medium. In a study by Salari et al., functional safety was assessed to be $60.51 \%$, a value with which our results agreed (24). Furthermore, in a study by Vali (25) and Amarion (26), functional safety was reported to be medium, as it was in our study. However, in the study conducted by Seyedin et al. on vulnerability to earthquakes of general hospitals associated with Tehran University of Medical Sciences, functional safety was reported to be $77.16 \%$ in six hospitals (27), which was different from our results. The low preparedness of hospitals in this domain could be related to various factors, including the lack of a written plan for administrative measures and contingency plans for medical treatment. This preparedness could be improved by providing written plans and training the staff to increase their knowledge in this domain. The results of our study showed that non-structural safety in the two hospitals we studied was $67.61 \%$, which was high, and the highest preparedness was related to the water supply system (85\%), while the lowest was related to (fixed and movable) office equipment and furnishings. In a study conducted by Seyedin et al., non-structural safety of Tehran hospitals against disasters was reported as undesirable, and the highest preparedness was related to medical gases index, with the lowest being related to fire detection and extinguishers (25); the results of our study were not in agreement with their results. In addition, in a study by Glif et al., the highest preparedness in non-structural susceptibility was $83 \%$ related to telecommunications (20), and the results of our study were not in agreement with their findings. In a study by Sabzghabaie and Mohammadi Yeganeh, non-structural preparedness was $14.86 \%$ out of 30 (their standard index) and $54 \%$, respectively $(21,28)$, and our findings were different. While non-structural components do not have a direct effect on a hospital's performance, their destruction during disasters could create serious disorder in performance of different parts of a hospital. Undoubtedly, displacement and destruction of facilities and equipment could be dangerous and risky for the staff, patients, and visitors. Even when a structure is resistant against disasters and is not destroyed by severe shaking, unsafe and unprincipled installation of office and medical equipment is dangerous. Therefore, it is apparent that preparedness must be increased in this domain. In this study, the structural safety of two hospitals was assessed to be $76.16 \%$, i.e., high safety. In Zhong et al.'s study, hospital structural safety was assessed to be good (22), as was the case in our study. In studies by Amiri (29), Sabzeghabaei (21), and Mirzaei (16), structural safety was assessed to be 43.8\%, 25.78 and 29.3 out of 50, respectively, which were of medium safety. However, it was weak in Rabeian's (30) study. Low preparedness in this domain was the result of various factors, including old hospitals, failure to identify the vulnerability of each building in the hospital, failure to identify the risk of each structure in the hospital, failure to identify possible structural reinforcement and its high costs, and not providing a list of structures at risk.

The limitations of this study include not selecting all hospitals because of high number of questions in the checklist of risk assessment that the experts in each filed were required to complete. However, we attempted to solve the problems related to completing the checklists in the two hospitals by employing experts in each domain. Among the shortcomings of the study was the fact that we could not assess all state hospitals. Therefore, it is suggested that the other hospitals in the Province be studied in the future.

\section{Conclusions}

The finding of this study showed relatively high preparedness of the hospitals we studied in Qazvin Province. The practical importance of these findings lies in more attention of senior managers of the Province and hospitals to cope with disasters as well as making the hospitals better prepared. It is suggested that the hospitals preparedness against unexpected disasters be increased by retrofitting the hospitals providing written plans for administrative measures when a disaster occurs, and the safe installation of furniture and medical equipment so the hospitals could continue to operate during a disaster to reduce the related mortality rate. An additional study of other hospitals in the Province using the checklist developed in this study could be an appropriate path for later studies in this domain.

\section{Acknowledgments:}

This study was part of a M.Sc. thesis in health services management of Qazvin. The author of this paper appreciates Mr. Adhami, Manager of Rajaee Hospital and Mr. Lotfi, the Head of the Crisis Committee, for their great effort in 
coordinating with other parts of the hospital to complete the checklists. We also express our appreciation to the many others who helped us in conducting this study.

\section{Conflict of Interest:}

There is no conflict of interest to be declared.

\section{Authors' contributions:}

All authors contributed to this project and article equally. All authors read and approved the final manuscript.

\section{References}

1) Munich Re. Natural catastrophes 2011.Analyses, assessments, positions. Topics Geo. 2012. Available from: http://earthmind.org/files/risk/MunichRe-2012-Natural-Catastrophes-2011.pdf

2) Guha-Sapir D, Vos F, Below R, Ponserre S. Annual Disaster Statistical Review 2011-The Numbers and Trends, Centre for Research on the Epidemiology of Disasters (CRED), Institute Of Health And Society (Irss), Universite Catholique De Louvain-Brussels, Belgium. Available From: http://Www.Cred.Be/Publications (Accessed 20/01/2014).

3) Jahangiri K, Tabibi S, Maleki MR, Alamdari SH. A comparative study on community-based disaster management $(\mathrm{cbdm})$ in selected countries and proposing a model for iran. Payesh Journal. 2009; 8(1): 4957

4) Hojat M. Disaster Management In Hospital. Tehran: Boshra Publication; 2010.

5) World Health Organization Regional Office for Eastern Mediterranean, Strategy-resolution. Emergency Preparedness and Humanitarian Actions. Resolutions. Available from: http://www.emro.who.int/emergency/strategy

6) Zhong S, Clark M, Hou XY, Zang YL, Fitzgerald G. Development of hospital disaster resilience: Conceptual framework and potential measurement. Emerg. Med J. 2014; 31(11): 930-8. doi: 10.1136/emermed-2012-202282, PMID: 24028975.

7) Shayan Z, Asef Zade S, Youelefi M. Evaluation of hospital emergency response to the disaster in the health centers of Qazvin University of Medical Sciences based on who:2012. Scientific Journal of Rescue \& Relief. 2013; 6(2); 21-31.

8) Barbera JA, Yeatts DJ, Macintyre AG. Challenge of hospital emergency preparedness: analysis and recommendations. Disaster Med Public Health Prep. 2009; 3(1): $74 . \quad$ doi: 10.1097/DMP.0b013e31819f754c, PMID: 19491592.

9) Hospitals Safe from Disasters, Reduce Risk, Protect Health Facilities, Save Lives, 2008-2009 World Disaster Reduction Campaign. Available from: https:/www.unisdr.org/2009/campaign/pdf/wdrc-20082009-information-kit.pdf

10) Pan American health organization. Hospital safety index: Guide for evaluators. The organization. 2008; 110. Available from: http://www.paho.org/english/dd/ped/SafeHosEvaluatorGuideE ng.pdf. Accessed: 9/9/2010

11) World Health Organization. Hospitals Safe Index Guide For Evaluators- 2nd ed; 2015. Available from: http://www.who.int.

12) Ferner H, Wemyss M, Baird A, Beer A, Hunter D. Seismic performance of non-structural elements within buildings. Proceeding Of The Nzsee Conference. 2014 march 21-23: 629-638.

13) World Health Organization (WHO). Epidemiology and disease control division (EDCD), Ministry of Health, Department of Health Services, Nepal. Guidelines for non-structural safety in health facilities. The organization. 2004: 28. Available from: http://apps.searo.who.int/PDS_DOCS/B0611.Pdf

14) World Health Organization (WHO) regional office for the western pacific. Field manual for capacity assessment of health facilities in responding to emergencies. 2006: 190. Available from: http://apps.who.int/bookorders/anglais/detart1.jsp?codlan=1\&codcol=52\&codcch=98

15) Pan American Health Organization (PAHO). Hospital Safety Index: Evaluation forms for safe hospitals. The organization. 2008: 36. Available from: http://www.paho.org/disasters

16) Mirzaei F, Kakae Hi, Farasaty F, Zamani N. Investigation on the Safety Status and Preparedness of Ilam's Hospitals against Disasters in 2012. Scientific Journal of Ilam University of Medical Sciences. 2014; 22(7): 14-23.

17) National geoscience database of Iran. Available from: http://www.ngdir.ir/Earthquake/EarthquakeList.asp 
18) Ardalan A, Najafi A, Sabzghabaie A, Zonoobi V, Ardalan S, Khankeh H, et al . A pilot study: Development of a local model to hospital disaster risk assessment. jhosp. 2011; 9 (3 and 4): 7-14. available from: http://jhosp.tums.ac.ir/browse.php?a code=A-10-25-73\&slc lang=en\&sid=1

19) Ardalan A, Kandi M, Talebian MT, Khankeh HR, Masoumi G, Mohammadi R, et al. Hospitals Safety from Disasters in I.R.Iran: The Results from Assessment of 224 Hospitals. PLoS Curr. 2014. Edition 1. 2014. doi: 10.1371/currents.dis.8297b528bd45975bc6291804747ee5db, PMID: 24596661.

20) Cliff BJ, Morlock L, Curtis AB. Is there an association between risk perception and disaster preparedness in rural US hospitals? Prehosp Disaster Med. 2009; 24(6): 512-7, PMID: 20301069.

21) Sabzghabaie A, Kondori A, Shojaee M, kamranirad A, Amini A, Hatamabadi HR. Hospital safety in hospitals affiliated with Shahid Beheshti University of Medical Sciences in 2011-13. Pejouhandeh. 2013; 18(2): 83-7. Available from: http://pajoohande.sbmu.ac.ir/browse.php?a_code=A-10-1$783 \&$ slc_lang $=$ en\&sid $=1$

22) Zhong S, Clark M, Hou X, Zang Y, FitzGerald G. Validation of a Framework for Measuring Hospital Disaster Resilience Using Factor Analysis. Int J Environ Res Public Health. 2014; 11(6): 6335-53. doi: 10.3390/ijerph110606335, PMCID: PMC4078582.

23) Jagnarine SH. Safe hospitals in Caribbean. Pan American Health Organization. 2014. Available from: http://www.jm.undp.org/content/dam/jamaica/docs/environment/SeismicForum2014/ShaliniJangnarineSafeHospitalsProgramme.pdf

24) Salari H, Heidari AR, Jolaee H, Rahimi SH, Shafaghat T. Readiness of governmental and private hospitals of Shiraz to deal with disasters in 2009. Scientific Journal of Rescue \& Relief. 2011; 2(4): 1-10.

25) Vali L, Masoud A, JabariBeyrami H, Yaghobian B. Readiness of hospitals affiliated with Tabriz University of Medical Sciences to Face Disasters. Journal of Health \& Development. 2014; 3(1): 62-70.

26) Amarion A, Aghighi A, Tofighi S, Sadeghi A, Shahedi A, Rasekh F, ea al. Assess The Disaster Preparedness Of The Selected Military Hospita. Ann Mil Health Sci Res. 2013; 11(4): 353-6. Available from: http://www.yektawebsite.ir/ ajaumsjour/browse.php?a_code=A-10-789-2\&slc_lang=en\&sid=1.

27) Seyedin H, Abasi Dolat Abadi Z, Sorani M, Naghdi S, Rajabfard Mazraeno F. Vulnerability assessment of general hospitals of Tehran University of Medical Sciences. JHPM. 2014; 3(2): 65-71. Available from: http://jhpm.ir/browse.php?a_code=A-10-420-1\&slc_lang=en\&sid=1\&sw=Safety

28) Mohammadi yeganeh sh, asadi lari M, Seyedin H, Maher A. Assess the quality and quantity of equipment and the vulnerability of non-public hospitals in Tehran during an earthquake. Scientific Journal of Rescue \& Relief. 2011; 3(1,2): 1-9.

29) Amiri M, Mohammadi Gh, Khosravi A, Chaman R, Arabi M, Sadeghi E, et al. Hospital Preparedness of Semnan Province to Deal with Disasters. Knowledge \& Health. 2011; 6(3): 44-9.

30) Rabeian M, Hosseini SH, Radabadi M, Taheri Mirghaed M, Bakhtiari M. Evaluation Of Effective Factors On The Rate Of Preparedness Of Tehran University Of Medical Sciences' Selected Hospitals In Dealing With Earthquake. Payavard Salamat. 2013; 7(3): 251-61. Available from: http://payavard.tums.ac.ir/browse.php?a_code=A-10-1-28\&slc_lang=fa\&sid=fa 